\title{
Study of Interleukin-18 in Chronic hepatitis C virus related liver diseases
}

\author{
Mohamed Alaa El-Din Nouh ${ }^{1}$, Hatem Mahmoud El-Sebaai ${ }^{2}$, \\ Hossam Ibrahim Mohamed ${ }^{1}$, Hossam El-Din Mostafa Seleem ${ }^{1}$, \\ Usama Khalil Khalil ${ }^{3}$ \\ ${ }^{1}$ Tropical Medicine Department, Faculty of Medicine, Menofia University, Egypt \\ ${ }^{2}$ Biochemistry Department, Faculty of Medicine, Menofia University, Egypt \\ ${ }^{3}$ Mansoura Fever Hospital, Mansoura, Egypt
}

Corresponding Author

Usama Khalil Khalil

Mobile:

$+201014920805$

E mail:

usama620@hotmail. com

Key words: Interleukin, Hepatitis C, ELISA, Cirrhosis
Background and study aim: ELISA can determine serum Interleukin (IL)-18 level. It is a sensitive, simple and rapid test, thus help to study changes of serum IL-18 levels in chronic HCV related liver diseases during different stages. The objective of this study was to study serum IL-18 levels in chronic HCV related liver diseases.

Patients and methods: Sera from 60 patients with $\mathrm{HCV}$ related chronic liver diseases at various stages of $\mathrm{HCV}$ infection (chronic hepatitis, cirrhosis and complications) and sera of 10 normal controls were subjected to measurements of serum IL-18 level by ELISA assay.
Results: There were highly significant increase in the mean values of serum IL18 in chronic HCV related liver cirrhosis, non complicated and complicated patients in comparison to chronic active hepatitis $\mathrm{C}$ patients and healthy subjects and highly significant increase in the mean values of serum IL-18 in complicated patients in comparison to non complicated patients. There was highly significant increase in the mean values of serum IL-18 in decompensated liver cirrhosis patients when compared to compensated patients.

Conclusion: Serum IL-18 level shows highly positive significant correlation with severity of liver dysfunction in $\mathrm{HCV}$ related liver cirrhosis.

\section{INTRODUCTION}

Hepatitis C (HCV) virus infection is a major cause of chronic liver disease worldwide, up to $70 \%$ of patients develop chronic infection which, in $20 \%$ of cases, will progress to cirrhosis and finally to hepatocellular carcinoma [1].

Indeed, HCV is not directly cytopathic, and the mechanisms by which it causes liver injury are not well established. Immune response that essentially conducted by cytokines may play an important role in the pathogenesis of HCV infection [2].

A strong T-helper lymphocyte-cell response, characterized by the production of interleukin-2, tumor necrosis factor-alpha and interferongamma, seems to be associated with HCV clearance; however, in the context of a persistent infection, they may be responsible for liver damage [3].

Cytokines genes are polymorphic at specific sites, and some of these mutations have been associated with inter-individual variations of cytokine expression. The Interleukin (IL)-18 gene is located on chromosome 11q22.2q22.3 and a variety of single nucleotide polymorphisms have been detected within IL-18 gene sequence. Several of these polymorphisms, especially those located in the promoter region, may be associated with differential levels of gene transcription [4].

IL-18 first identified as an IFN- $\gamma$ inducing factor, is mainly produced by activated macrophages and Kuffer cells, and plays a strategic role in inflammation and liver injury. It exerts a proinflammatory activity by enhancing 
the Fas ligand and perforin-mediated T-cell and natural killer-cell cytotoxicity, stimulating $\mathrm{Th}_{1^{-}}$ cell development, inducing chemokines, and decreasing IL-10 expression in T cells. Besides, IL-18 increases the susceptibility of liver endothelial cells to undergo apoptosis [5].

In chronic hepatitis $\mathrm{C}$ and cirrhosis, an increase in the expression of proinflammatory cytokines, in particular IL-18, has been shown, which correlates with IFN- $\gamma$ production [6].

The objective of this study was to study serum IL-18 levels in chronic HCV related liver diseases.

\section{PATIENTS AND METHODS}

This study was carried out in Tropical Medicine Department, Faculty of Medicine, Menofia University Hospitals. The study was conducted on four groups: Group I: Included twenty patients with chronic active hepatitis $\mathrm{C}$ were selected from patients waiting the interferon based antiviral treatment; all performed liver biopsy and showed hisopathological features of chronic active hepatitis. Group II: Included twenty patients with chronic HCV related non complicated liver cirrhosis (compensated or decompensated). Group III: Included twenty patients with complicated chronic HCV related liver cirrhosis. Group IV: Included ten healthy persons of matched age and sex as control group. After having an informed consent; each patient underwent: Detailed history taking, thorough clinical examination, laboratory investigations including liver profile tests (ALT, AST, bilirubin, serum albumin and INR), viral markers (HCV antibody, $\mathrm{HBsAg}$ ), quantitative $\mathrm{HCV}$ RNA by the PCR, serum alpha-fetoprotein, imaging study (abdominal ultrasonography and triphasic CT scan for HCC patients) and measurement of serum IL-18 using ELISA kit.

\section{Exclusion criteria:}

Patients with chronic liver diseases due to any cause other than chronic HCV and patients with any disease known to affect serum level of IL-18 (chronic infection, diabetes mellitus, renal failure, coronary heart disease, other malignancies, etc) were excluded from the present study.

\section{Statistical analysis:}

Data were collected, tabulated and statistically analyzed by computer data using SPSS (Statistical Package for Social Sciences) version 15. Qualitative data were presented as number and percent. Comparison between groups was done by ChiSquare test. Quantitative data were tested for normality by Kolmogrov-Smirnov test. Normally distributed data were presented as mean \pm SD. Student t-test was used to compare between two groups. F-test (One Way Anova) was used to compare between more than two groups. Pearson's correlation coefficient was used to test correlation between variables. $\mathrm{P}<0.05$ was considered to be statistically significant.

\section{RESULTS}

No statistically significant differences were reported among the studied groups as regarding age and sex as shown in Table (1).

There were a highly significant increases in the mean values of serum IL-18 in chronic HCV related liver cirrhosis, non complicated and complicated patients in comparison to chronic active hepatitis $\mathrm{C}$ patients and healthy subjects. Also, there was a highly significant increase in the mean values of serum IL-18 in complicated patients in comparison to non complicated patients as shown in Table (2).

It is obvious from our results that IL-18 correlates with progression of cirrhosis, where a highly significant increase in the mean values of serum IL-18 in decompensated liver cirrhosis patients was noticed when compared to compensated patients as shown in Table (3).

The serum IL-18 concentrations were related to the Child-Pugh severity of liver disease in cirrhotic patients as shown in Figure (1).

The complications of liver cirrhosis do have an impact on the level of IL-18. There was a highly significant increase in the mean values of serum IL-18 in cirrhotic patients complicated by HCC followed by cirrhotic patients complicated by hepatorenal syndrome (HRS) as shown in Table (4). 
Table (1): Age and sex distribution among studied groups

\begin{tabular}{|c|c|c|c|c|c|c|c|}
\hline \multirow{3}{*}{\begin{tabular}{|l|} 
\\
Group I
\end{tabular}} & \multicolumn{3}{|c|}{ Age } & \multicolumn{4}{|c|}{ Sex } \\
\hline & $\mathbf{N}$ & Mean \pm SD & Range & \multicolumn{2}{|c|}{ Male } & \multicolumn{2}{|c|}{ Female } \\
\hline & 20 & $48.55 \pm 5.79$ & $41-60$ & 14 & $70 \%$ & 6 & $30 \%$ \\
\hline Group II & 20 & $52.45 \pm 7.37$ & $39-63$ & 13 & $65 \%$ & 7 & $35 \%$ \\
\hline Group III & 20 & $51.00 \pm 6.71$ & $38-61$ & 12 & $60 \%$ & 8 & $40 \%$ \\
\hline Group IV & 10 & $51.10 \pm 6.90$ & $43-62$ & 5 & $50 \%$ & 5 & $50 \%$ \\
\hline Test & \multicolumn{3}{|c|}{$F=1.170$} & \multicolumn{4}{|c|}{$\chi^{2}=1.254$} \\
\hline$P$ value & \multicolumn{3}{|c|}{0.328} & \multicolumn{4}{|c|}{0.740} \\
\hline
\end{tabular}

Table (2): Mean values of serum IL-18 among the studied groups

\begin{tabular}{|l|c|c|c|c|}
\hline \multicolumn{1}{|c|}{ Groups } & $\begin{array}{c}\text { Group 1 } \\
(\mathbf{n = 2 0})\end{array}$ & $\begin{array}{c}\text { Group II } \\
(\mathbf{n = 2 0})\end{array}$ & $\begin{array}{c}\text { Group III } \\
(\mathbf{n = 2 0})\end{array}$ & $\begin{array}{c}\text { Group IV } \\
(\mathbf{n = 1 0})\end{array}$ \\
\hline M \pm SD & $367.10 \pm 64.68$ & $743.95 \pm 132.62$ & $1133.55 \pm 273.47$ & $289.50 \pm 40.26$ \\
\hline Range & $254-450$ & $553-1129$ & $815-1670$ & $224-345$ \\
\hline F. test & \multicolumn{3}{|c|}{$\mathbf{9 1 . 3 5 3}$} \\
\hline P. value & \multicolumn{3}{|c|}{$<\mathbf{0 . 0 0 1}$} \\
\hline & \multicolumn{3}{|c}{ GI \& GII** GI \& GIII** } \\
LSD test & GII \& GIII** GII \& GIV** \\
& GIII \& GIV** \\
\hline
\end{tabular}

$\checkmark$ Least significant difference test.

* Significant ** Highly significant

Table (3): Mean values of serum IL-18 in group II patients in relation to the state of decompensation

\begin{tabular}{|l|c|c|c|c|c|}
\hline \multirow{2}{*}{\multicolumn{1}{|c|}{ Group II }} & \multicolumn{5}{|c|}{ IL-18 } \\
\cline { 2 - 5 } & N & Mean \pm SD & Range & t & P \\
\hline Compensated & 11 & $652.09 \pm 57.69$ & $553-739$ & \multirow{2}{*}{5.388} & $<0.001^{*}$ \\
\hline Decompensated & 9 & $856.22 \pm 108.76$ & $763-1129$ & & \multirow{2}{*}{} \\
\hline
\end{tabular}

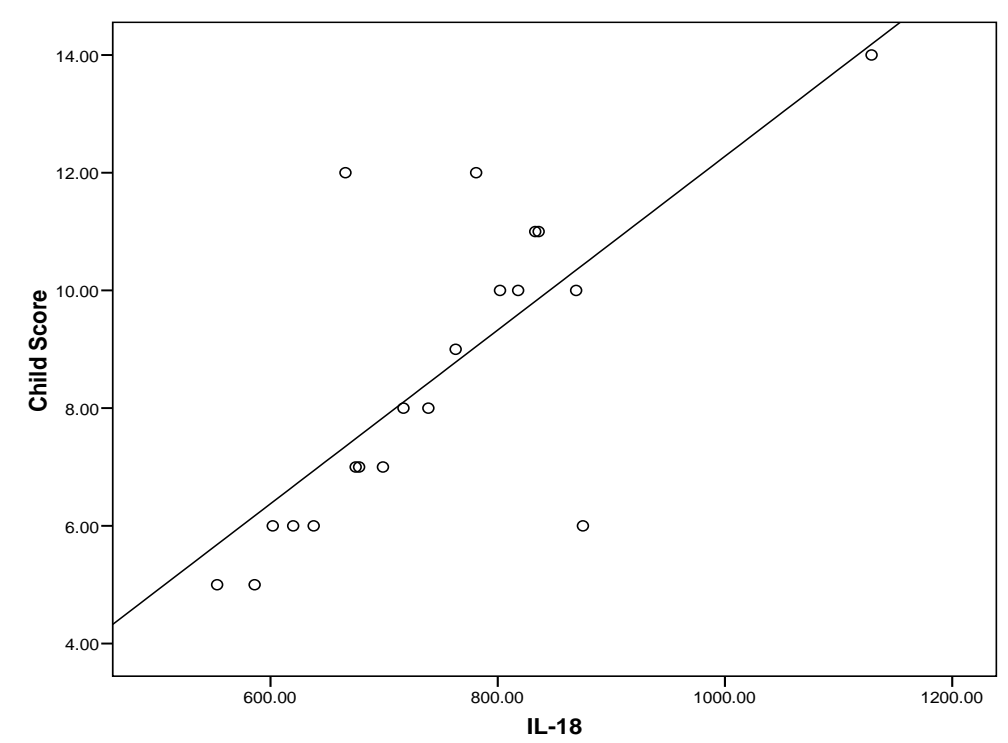

Figure (1): Shows highly significant positive correlation between Child-

Pugh score and serum IL-18 level in group II patients. 
Table (4): Mean values of serum IL-18 in group III patients in relation to types of complications

\begin{tabular}{|c|c|c|c|}
\hline IL-18 & $\begin{array}{c}\text { HCC } \\
(n=7)\end{array}$ & $\begin{array}{c}\text { HRS } \\
(n=6)\end{array}$ & $\begin{array}{c}\text { SBP } \\
(n=7)\end{array}$ \\
\hline $\mathbf{M} \pm$ SD & $1439.14 \pm 182.23$ & $1084.43 \pm 103.08$ & $870.14 \pm 49.34$ \\
\hline Range & $1262-1670$ & $965-1238$ & $815-950$ \\
\hline F. test & \multicolumn{3}{|c|}{36.737} \\
\hline P. value & \multicolumn{3}{|c|}{$<0.001$} \\
\hline LSD test & \multicolumn{3}{|c|}{ HCC \& HRS** - HCC \& SBP** - HRS \& SBP** } \\
\hline
\end{tabular}

HCC; Hepatocellular Carcinoma, HRS; Hepatorenal Syndrome, SBP; spontaneous Bacterial Peritonitis

\section{DISCUSSION}

$\mathrm{HCV}$ infection leads to chronic liver disease in $70 \%$ of infected patients, who may develop cirrhosis and HCC during the course of infection. Persistent liver inflammation is strongly associated with HCV-mediated liver disease progression and also increases the risk of an aggravated immune response and fibrosis [7].

IL-18 increases the susceptibility of liver endothelial cells to undergo apoptosis. Significant evidences indicating that IL-18 plays a prominent role in liver injury were reported [8]. The present study showed highly significant increase in the mean values of serum IL-18 in chronic HCV related liver cirrhosis, non complicated and complicated patients in comparison to chronic active hepatitis $\mathrm{C}$ patients and healthy subjects. These findings were in agreement with Jia et al. [9] who reported that patients with chronic hepatitis $\mathrm{C}$ had significantly higher serum levels of IL-18 compared with asymptomatic HCV carriers and controls by studying serum IL-18, IL-10 and sIL-2R levels in 27 patients with chronic hepatitis $\mathrm{C}$ and 24 asymptomatic $\mathrm{HCV}$ carriers in addition 10 healthy individuals. Suggesting that IL-18 and tested cytokines co-participate in the pathogenesis of chronic hepatitis C. Similarly, Sharma et al. [10] reported that the mean levels of IL-18 were significantly elevated in patients with chronic hepatitis $\mathrm{C}$ and HCV-related cirrhosis when compared with the normal controls.

The difference between the chronic hepatitis and cirrhotic groups was also significant. IL-18 protein production was quantified in serum samples from 50 patients in different stages of HCV infection and compared with 15 normal healthy controls. As necrosis and fibrosis are associated, independent correlations in only six patients, in whom IL-18 levels were strongly related to necroinflammation. Thus, the pathological consequences of infection mediated by IL-18 are clearly detrimental to the host.
Also, Bouzgarrou et al. [11] reported that plasma levels of IL-18 were elevated in chronic active hepatitis $\mathrm{C}$ patients than healthy controls, cirrhotic patients had higher levels than non cirrhotic patients and elevated in HCC patients than cirrhotic patients. Moreover, Selim et al. [12] reported that IL18 levels are elevated in chronic hepatitis C patients than in healthy subjects. IL-18 level is significantly increased with the increase in the histological stage of fibrosis, disease progression is accompanied by an increase in plasma IL-18 and strongly support the involvement of IL-18 in causing liver injury. Thus IL-18 could be used and nominated as an additional non invasive marker for monitoring the degree of liver fibrosis in chronic hepatitis $\mathrm{C}$ patients.

Statistical analysis revealed highly significant increase in the mean values of serum IL-18 in decompensated liver cirrhosis patients when compared to compensated patients and highly significant positive correlation between ChildPugh score and serum IL-18 level in group II patients. These results are in agreement with Urushihara et al. [13] who reported that serum level of IL-18 in patients with HCV as disease progressed from non cirrhotic to cirrhotic as well as with deterioration of cirrhosis from ChildPugh stage A to stage Child-B and then to stage Child-C, further increased IL-18 serum levels were observed. Similarity, Tilg and Diehl [14] found that plasma IL-18 levels were increased with disease progression independent of the etiology of chronic liver disease.

IL-18 mRNA expression was significantly upregulated in the peripheral blood mononuclear cells (PBMC) of cirrhotic patients when compared with other groups, while in the liver, higher levels of IL-18 transcripts were expressed in patients with chronic hepatitis $\mathrm{C}$. The results indicate that IL-18 levels reflect the severity and activity of $\mathrm{HCV}$ infection, and may contribute to the pathogenesis and progression of liver disease 
associated with $\mathrm{HCV}$, deterioration of cirrhosis from compensated stage to stage of decompensation, further increased IL-18 serum levels were observed [10]. Interestingly, IL-18 binding protein (IL-18BP) levels paralleled the increase of IL-18 with disease progression. Only in stage Child C were IL-18BP levels decreased, while IL-18 levels were still increased [15].

Statistical analysis of this study revealed highly significant increase in the mean values of serum IL-18 in patients with HCC as compared to other cirrhotic complications. And highly significant increase in the mean values of serum IL-18 in patients with hepatorenal syndrome (HRS) as compared to patients with spontaneous bacterial peritonitis. Although patients with spontaneous bacterial peritonitis (SBP) show lowest level of serum IL-18 as compared to other cirrhotic complications but higher than patients with liver cirrhosis without SBP. These results are in agreement with Yumoto et al. [16] who reported that serum IL-18 and IFN- $\gamma$ levels were significantly increased in patients with HCC than in patients with chronic viral hepatitis, liver cirrhosis and healthy volunteers. The authors suggested that IL-18 and IFN- $\gamma$ may be involved in the pathogenesis of hepatic carcinogenesis.

Similarity, Hamouda et al. [17] reported that serum IL-18 increased significantly in patients of $\mathrm{HCC}$ complicating $\mathrm{HCV}$ related cirrhosis more than chronic HCV patients (with or without cirrhosis) and healthy subjects. The study was conducted on fifty subjects by measuring serum IL-18 level in patients and control classified into four groups (chronic HCV infection without liver cirrhosis, chronic HCV infection with liver cirrhosis, HCC on top of chronic HCV liver cirrhosis and healthy subjects). Moreover, Ahmed et al. [18] reported that serum levels of IL-18 are elevated in HCC patients than in healthy subjects. IL-18 level is significantly increased with the increase in the tumor size and its concentration may predict the degree of hepatocellular damage. Thus IL- 18 could be used and nominated as an additional non invasive marker for monitoring the degree of liver damage.

The significant increase in the mean value of IL18 in cirrhotic patients complicated by HRS in the present study were in agreement with Qasem et al. [19] who reported that IL-18 in HRS patients were higher than those of patients with liver cirrhosis and chronic hepatitis. The authors reported that serum creatinine is a poor biomarker for early detection of renal impairment in cirrhotic patients while IL-18 was early biomarker of acute kidney injury in cirrhotic patients.

The significant increase in the mean value of IL18 in cirrhotic patients complicated by SBP in the present study was in agreement with Shin et al. [20] who reported that serum IL-18 in patients with SBP was significantly more elevated than in patients with liver cirrhosis and than healthy volunteers. IL-18 concentration was significantly increased in cirrhotic patients who developed SBP, in those with culture-positive peritonitis, and in those who developed organ failure, as compared with the other patients.

\section{CONCLUSION}

Serum IL-18 level shows highly positive significant correlation with severity of liver dysfunction in $\mathrm{HCV}$ related liver cirrhosis. Serum IL-18 may play a role in pathogenesis of hepatic decompensation and occurrence of hepatic complications in patients with $\mathrm{HCV}$ related cirrhosis.

\section{REFERENCES}

1. Rehermann, Nascimbeni. Immunology of hepatitis $\mathrm{B}$ virus and hepatitis $\mathrm{C}$ virus infection. Nat Rev Immunol 2005; 5: 215-229

2. Neuman MG, Benhamou JP, Marcellin P, Valla D, Malkiewicz IM, Katz GG, et al. Cytokinechemokine and apoptotic signatures in patients with hepatitis C. Transl Res 2007;149:126-136.

3. Cramp ME, Rossol S, Chokshi S, Carucci P, Williams R, Maoumov NV, et al. Hepatitis C virus-specific $\mathrm{T}$-cell reactivity during interferon and ribavirin treatment in chronic hepatitis $\mathrm{C}$. Gastroenterology 2000; 118:346-355.

4. Giedraitis V, He B, Huang WX, Hillert J. Cloning and mutation analysis of the human IL18 promoter: a possible role of polymorphisms in expression regulation. J Neuroimmunol 2000; 112: 146-152.

5. Kanda N, Shimizu T, Tada Y, Watanabe S. IL-18 enhances INF-gamma-induced production of CXCL10, and CXCL11 in human keratinocytes. Eur J Immunol 2007; 37:338-350.

6. McGuinness PH, Painter D, Davies S, McCaughan GW. Increases in intrahepatic CD68 positive cells, MAC387 positive cells, and proinflammatory cytokines (particularly interleukin 18) in chronic hepatitis C infection. Gut 2000; 46: 260-9. 
7. Gravitz L. Introduction: a smouldering publichealth crisis. Nature 2011; 474: S2-S4.

8. Marino E, Cardier JE. Differential effect of IL-18 on endothelial cell apoptosis mediated by TNFalpha and Fas (CD95). Cytokine. 2003; 22:142-148.

9. Jia H, Du J, Zhu S, Ma Y, Cai H. Clinical observation of serum IL-18, IL-10 and sIL-2R levels in patients with chronic hepatitis $\mathrm{C}$ pre-and post antiviral treatment. Clin Med J 2003; 116: 605-608.

10. Sharma A, Chakraborti A, Das A, Dhiman RK, Chawla Y. Elevation of interleukin-18 in chronic hepatitis $\mathrm{C}$ : implications for hepatitis $\mathrm{C}$ virus pathogenesis. Immunology 2008; 128: 514-522.

11. Bouzgarrou N, Hassen E, Schvoerer E, StollKeller F, Bahri O, Gabbouj S, et al. Association of IL-18 polymorphisms and plasma level with the outcome of chronic $\mathrm{HCV}$ infection. J Med Virol 2008; 80: 607-14

12. Selim H, Mohamed A, Hossam A, Dina A. Evaluation of Interleukin-18 as a Non Invasive Marker of Liver Fibrosis among Chronic Hepatitis C Virus Patients. J Egypt Public Health Assoc 2009; 84: 392-403.

13. Urushihara N, Iwagaki H, Yagi T, Kohka H, Kobashi $\mathrm{K}$, Morimoto Y, et al. Elevation of serum interleukin18 levels and activation of Kupffer cells in biliary atresia. J Pediatr Surg 2000; 35:446-9.

14. Tilg H, Diehl AM. Cytokines in alcoholic and nonalcoholic steatohepatitis. $N$ Engl J Med 2006; 343:1467-1476.

15. Ludwiczek O, Kaser A, Novick D, Dinarello CA, Rubinstein M, Vogel W, et al. Plasma levels of Interleukin-18 and interleukin-18 binding protein are elevated in patiesnts with chronic liver disease. J. Clin. Immunol 2002; 22, 331-337.
16. Yumoto E, Higashi T, Nouso K, Nakatsukasa H, Fujiwara K, Hanafusa T, et al. Serum gammainterferon-inducing factor (IL-18) and IL-10 levels in patients with acute and chronic hepatitis and fulminant hepatic failure. J Gastroenterol Hepatol 2002; 17(3):285-94.

17. Hamouda S, Deghady A, Ayman F, Ghobashi R. Study of the serum Interleukin-18 in patients with chronic hepatitis $\mathrm{C}$ virus infection. Alexandria Bulletin 2006; 327.

18. Ahmed A, Maklad S, Hussein G, Badawy I, , Abou Zeid A, El-Feky S. Assessment of the Role of Interleukin-18 in diagnosis of Hepatocellular Carcinoma related to Hepatitis C Virus infection. Life Science Journal 2012; 8(4): 1154

19. Qasem A, Farag S, Hamed E, Emara M, Bihery A, Pasha H. Biomarkers of Acute Kidney Injury in Patients with Liver Cirrhosis. Journals of the ISRN Nephrology 2014; 376795: 7.

20. Shin I, Satoshi O, Manabu K, Hironori T, Akira M, Hidetaka M. Interleukin-18 concentration in the peritoneal fluid correlates with the severity of peritonitis. American Journal of Surgery 2003; 185: 550-555.

Peer reviewer: Salem Yousef Mohamed Lecturer Internal Medicine (Hepatology and Gastroentrology Unit), Faculty of Medicine, Zagazig University Egypt. Ibrahim Mohamed Ibrahim, Lecturer of Tropical Medicine and Hepatogastroenterology, Faculty of Medicine, Zagazig University, Egypt.

Editor: Mohamed H Emara, Lecturer of Tropical Medicine and Hepatogastroenterology, Faculty of Medicine, Zagazig University, Egypt 